\title{
Targeting immunoglobulin $E$ in non-atopic asthma: crossing the red line?
}

\author{
Mina Gaga ${ }^{1}$, Eleftherios Zervas ${ }^{1}$ and Marc Humbert $\mathbb{1}^{2,3,4}$
}

Affiliations: "7th Respiratory Medicine Dept and Asthma Center, Athens Chest Hospital "Sotiria", Athens, Greece. ${ }^{2}$ Univ. Paris-Sud, Université Paris-Saclay, Le Kremlin Bicêtre, France. ${ }^{3}$ Service de Pneumologie, Hôpital Bicêtre, Assistance Publique Hôpitaux de Paris, Le Kremlin Bicêtre, France. ${ }^{4}$ INSERM UMR S 999 , Hôpital Marie Lannelongue, Le Plessis Robinson, France.

Correspondence: Mina Gaga, 7th Respiratory Medicine Dept and Asthma Center, Athens Chest Hospital "Sotiria", 152 Mesogeion Ave, Athens 115 27, Greece. E-mail: minagagadyahoo.com

0 @ERSpublications

Use of omalizumab in severe non-atopic asthma: some positive data, but more research is needed http://ow.ly/iOla304uoin

Asthma is a heterogeneous disease on a clinical as well as a mechanistic level. A major molecular mechanism of asthma is considered to be driven by type 2 T-helper cells (Th2) and eosinophilic airway inflammation in both atopic and non-atopic asthma [1]. Over recent years, however, extensive research has revealed that Th2-low subtypes are also common, particularly in severe asthma [2-4]. These non-Th2 asthma endotype patients may not respond adequately to usual treatment, including glucocorticosteroids and novel targeted biologics such as anti-immunoglobulin E (IgE) and anti-interleukin 5 (IL-5), and there is an urgent need for further research and therapeutic options in this group of asthmatics [5].

In this issue of the European Respiratory Journal, Pillai et al. [6] present results from a small study examining the effects of anti-IgE treatment in severe non-atopic asthma. In this proof-of-concept study, omalizumab therapy reduces IgE expression and IgE sensitisation of target cells within the bronchial mucosa while exerting a favourable effect on lung function in the short term, as assessed by changes in forced expiratory volume in $1 \mathrm{~s}$ (FEV1). The authors conclude that omalizumab treatment may be beneficial in severe non-atopic asthma.

Researchers have been looking into mechanisms of non-atopic asthma and its relation to Th2-type cytokines, namely IL-4 and IL-5, for quite some time and there is a hypothesis that perhaps locally in the bronchi non-atopic asthma may in fact be linked with atopic mechanisms [7-9]. Airway eosinophilia has been a distinctive feature of asthma since the late 1800s, when Paul Ehrlich used eosin and demonstrated the presence of eosinophils in Charcot-Leyden crystals and in Curschmann's spirals. But it is over the past 30 years that the role of the eosinophil and the relationship with T-helper cell function in asthma has been established. This has been driven by major advances in immunology, molecular biology and imaging techniques, which enabled the characterisation of T-helper cells, the discovery and characterisation of cytokines and chemokines, and has also been driven by the work of many dedicated researchers worldwide. The discovery of IgE represented another major breakthrough in allergy and asthma research. Allergic airway inflammation is primarily a Th2-weighted process; however, there is heterogeneity in patterns of inflammation and endotypic distinctions that influence disease presentation and treatment effects.

Aspects of the complex link between IgE and asthma have been clarified by basic research and studies of the effect of anti-IgE biotherapy [10]. Today, the role of anti-IgE treatment with omalizumab is well established in allergic asthma with numerous clinical studies and meta-analyses demonstrating its clinical efficacy $[11,12]$. The concept of omalizumab treatment in non-atopic asthma is a new provocative idea and initially some case reports and data from severe asthma registries gave food for thought and discussion [13, 14]. The study by Pillai et al. [6] provides an insight into the possible anti-inflammatory

Received: Sept 112016 | Accepted: Sept 122016

Conflict of interest: Disclosures can be found alongside this article at erj.ersjournals.com

Copyright OERS 2016 
effects of omalizumab in non-atopic asthma. These data are in agreement with a recent proof-of-concept clinical trial by GARCIA et al. [15] examining the clinical effects of omalizumab in non-atopic asthmatics; they demonstrated an improvement in FEV1 and a trend towards improvement in clinical effectiveness and asthma exacerbation rate.

So, should we change the way we think and the way we treat our patients? In order for the guidelines to change, the evidence has to be based on large randomised controlled trials and the results of these trials should not be conflicting [16]. Let us look at the evidence regarding omalizumab therapy in non-atopic asthma at the moment: the vast majority of omalizumab studies have been performed in atopic asthma and the omalizumab label clearly indicates that this agent is approved for severe allergic asthmatics. Despite the fact that there are many similarities between atopic and non-atopic asthma, there is also substantial evidence from both research into severe asthma mechanisms as well as clinical studies that some asthma endotypes are non-Th2 [17].

Th2-low asthma is not as rare as was previously thought, especially among severe asthmatics. In the Belgian severe asthma registry, eosinophilic asthma was the predominant phenotype (55\%), but neutrophilic and paucigranulocytic asthma accounted for $22 \%$ and $17 \%$, respectively [18]. Moreover, low Th2 asthma, especially neutrophilic asthma, was associated with more severe disease, reduced pulmonary function and poor asthma control $[19,20]$. The mechanisms that drive Th2-low asthmatic inflammation are still not well characterised, but inherent airway smooth muscle abnormalities, and IL-8 and/or IL-17 mediated inflammatory processes have been proposed as possible pathways [21]. Moreover, Th2-low asthma is often associated with different harmful stimuli such as certain occupational exposures, smoking and viral infections, while atopy and IgE seem to play a minor role $[17,21]$. However, to add confusion to our thoughts, atopic asthma is not always Th2 high. In some cases, atopic asthma may also be Th2 low. The effectiveness of omalizumab in Th2-low atopic asthma has been questioned by the results of the study by HANANIA et al. [22], evaluating treatment effects of omalizumab in relation to exhaled nitric oxide fraction, blood eosinophils and serum periostin levels in a post hoc analysis of a large cohort of patients. The difference in exacerbation rate between omalizumab and placebo was less pronounced in atopic patients with low levels of Th2 biomarkers. So, in the face of possibly reduced efficacy of anti-IgE treatment in atopic asthmatics in the absence of Th2 biomarkers, there can obviously be doubts about its effectiveness in non-atopic asthma. However, exploring the effects of omalizumab in Th2-high non-atopic asthma in larger studies may be worth pursuing.

To conclude, there is now evidence suggesting that asthma pathways are usually Th2 driven and involve eosinophils, but there are also a substantial number of patients who have non-Th2 driven disease or patients who may alternate between Th2-high and Th2-low inflammation [23]. Therefore, it is important to review each patient meticulously and regularly and provide personalised and targeted treatment. Studies, such as the one performed by PILlaI et al. [6], demonstrate that unexpected effects may be shown by medications used outside of their specified recommendations. This is important for research; however, it is not acceptable in clinical practice, unless further evidence is provided by large conclusive studies. In the case of using omalizumab to treat non-atopic severe asthma, the evidence is not yet conclusive and clinical practice and recommendations will not be changed, at least not at the present time. In the era of personalised and targeted medicine, it is important to fully characterise our patients and prescribe treatment that aims at treating the particular patient. It is also important to follow guidelines and to consider the cost, taking into account the cost of medication, and the burden of the disease to the patient and to society both in terms of quality of life, absenteeism, future risk and disability.

\section{References}

1 Humbert M, Menz G, Ying S, et al. The immunopathology of extrinsic (atopic) and intrinsic (non-atopic) asthma: more similarities than differences. Immunol Today 1999; 20: 528-533.

2 Fleming L, Murray C, Bansal AT, et al. The burden of severe asthma in childhood and adolescence: results from the paediatric U-BIOPRED cohorts. Eur Respir J 2015; 46: 1322-1333.

3 Newby C, Heaney LG, Menzies-Gow A, et al. Statistical cluster analysis of the British Thoracic Society severe refractory asthma registry: clinical outcomes and phenotype stability. PLoS One 2014; 9: e102987.

4 Shaw DE, Sousa AR, Fowler SJ, et al. Clinical and inflammatory characteristics of the European U-BIOPRED adult severe asthma cohort. Eur Respir J 2015; 46: 1308-1321.

5 Chung KF, Wenzel SE, Brozek JL, et al. International ERS/ATS guidelines on definition, evaluation and treatment of severe asthma. Eur Respir J 2014; 43: 343-373.

6 Pillai P, Chan Y-C, Wu S-Y, et al. Omalizumab reduces bronchial mucosal IgE and improves lung function in non-atopic asthma. Eur Respir J 2016; 48: 1593-1601.

7 Humbert M, Durham SR, Ying S, et al. IL-4 and IL-5 mRNA and protein in bronchial biopsies from patients with atopic and nonatopic asthma: evidence against "intrinsic" asthma being a distinct immunopathologic entity. Am J Respir Crit Care Med 1996; 154: 1497-1504.

8 Ying S, Humbert M, Barkans J, et al. Expression of IL-4 and IL-5 mRNA and protein product by CD4 ${ }^{+}$and CD8 ${ }^{+}$ $\mathrm{T}$ cells, eosinophils, and mast cells in bronchial biopsies obtained from atopic and nonatopic (intrinsic) asthmatics. J Immunol 1997; 158: 3539-3544.

9 Menz G, Ying S, Durham SR, et al. Molecular concepts of IgE-initiated inflammation in atopic and nonatopic asthma. Allergy 1998; 53: Suppl., 15-21. 
10 Froidure A, Mouthuy J, Durham SR, et al. Asthma phenotypes and IgE responses. Eur Respir J 2016; 47: 304-319.

11 Humbert M, Busse W, Hanania NA, et al. Omalizumab in asthma: an update on recent developments. J Allergy Clin Immunol Pract 2014; 2: 525-536.

12 Samitas K, Delimpoura V, Zervas E, et al. Anti-IgE treatment, airway inflammation and remodelling in severe allergic asthma: current knowledge and future perspectives. Eur Respir Rev 2015; 24: 594-601.

13 Menzella F, Piro R, Facciolongo N, et al. Long-term benefits of omalizumab in a patient with severe non-allergic asthma. Allergy Asthma Clin Immunol 2011; 7: 9.

14 de Llano LP, Vennera MC, Alvarez FJ, et al. Effects of omalizumab in non-atopic asthma: results from a Spanish multicenter registry. J Asthma 2013; 50: 296-301.

15 Garcia G, Magnan A, Chiron R, et al. A proof-of-concept, randomized, controlled trial of omalizumab in patients with severe, difficult-to-control, nonatopic asthma. Chest 2013; 144: 411-419.

16 Reddel HK, Bateman ED, Becker A, et al. A summary of the new GINA strategy: a roadmap to asthma control. Eur Respir J 2015; 46: 622-639.

17 Lin TY, Poon AH, Hamid Q. Asthma phenotypes and endotypes. Curr Opin Pulm Med 2013; 19: 18-23.

18 Schleich F, Brusselle G, Louis R, et al. Heterogeneity of phenotypes in severe asthmatics. The Belgian Severe Asthma Registry (BSAR). Respir Med 2014; 108: 1723-1732.

19 Moore WC, Hastie AT, Li X, et al. Sputum neutrophil counts are associated with more severe asthma phenotypes using cluster analysis. J Allergy Clin Immunol 2014; 133: 1557-1563.

20 The ENFUMOSA cross-sectional European multicentre study of the clinical phenotype of chronic severe asthma. European Network for Understanding Mechanisms of Severe Asthma. Eur Respir J 2003; 22: 470-477.

21 Samitas K, Zervas E, Gaga M. T2-low asthma: current approach to diagnosis and therapy. Curr Opin Pulm Med 2017; in press [DOI: 10.1097/MCP.0000000000000342].

22 Hanania NA, Wenzel S, Rosen K, et al. Exploring the effects of omalizumab in allergic asthma: an analysis of biomarkers in the EXTRA study. Am J Respir Crit Care Med 2013; 187: 804-811.

23 Kupczyk M, Dahlen B, Sterk PJ, et al. Stability of phenotypes defined by physiological variables and biomarkers in adults with asthma. Allergy 2014; 69: 1198-1204. 